\title{
STRATEGI PENGEMBANGAN PASAR KERAMIK BELAWAN SEBAGAI DAYA TARIK WISATA BELANJA DI KOTA MEDAN
}

\author{
Femmy Indriany Dalimunthe ${ }^{1}$ \\ Politeknik Pariwisata Medan \\ femmydalimunthe@gmail.com \\ Anwari Masatip ${ }^{2}$ \\ Politeknik Pariwisata Medan \\ anm_stpb@yahoo.com \\ Liyushiana $^{3}$ \\ Politeknik Pariwisata Medan \\ liyushiana@gmail.com \\ Dina Rosari ${ }^{4}$ \\ Politeknik Pariwisata Medan \\ dinar15akparmedan@gmail.com
}

Received: December 17, 2019/ Reviewed: March 27, 2020/ Published: May 6, 2020

17 Desember 2019

\begin{abstract}
This study aims to identify the strategic assumptions of Belawan Ceramics Market with a descriptive method approach. By compiling results from the perspective of customers and traders, this study analyzes strategic assumptions with the SWOT analysis tool. The results showed that consumers who came were consumers who had repeatedly visited the Ceramic Market, but the loyalty of visitors decreased for the fourth visit. Tourist considerations for visiting the Belawan Ceramics Market are diverse types of merchandise, traditional bargaining systems, interactions with direct traders, as well as structuring shopping space that is not rigid with social accessibility in the form of local community acceptance (especially traders) towards foreigners. From the SWOT analysis conducted, it was found that the strategies that could be carried out to develop the Belawan ceramics market were: opening stores early, adding collections of unique items, expanding promotions through social media, pentahelix synergy for more effective development, price competition considerations in accordance with the quality of the goods being marketed, complementing supporting tourism utilities such as lighting facilities and increasing the role of government and community self-help to increase the sense of security for visitors / tourists.
\end{abstract}

Keywords : development, shopping tourism, SWOT analysis

*correspondence author, email: femmydalimunthe@gmail.com 


\title{
Naskah diterima: 17 Desember 2019/ Naskah ditelaah : 27 Maret 2020/ Naskah dipublikasi : 6 Mei 2020
}

\begin{abstract}
ABSTRAK
Tujuan dari penelitian ini adalah untuk mengidentifikasi asumsi stratejik pengembangan Pasar Keramik Belawan dengan pendekatan metode deskriptif. Dengan mengkompilasi hasil dari perspektif pelanggan dan pedagang, penelitian ini menganalisis asumsi stratejik dengan perangkat analisis SWOT. Hasil penelitian menunjukkan bahwa konsumen yang datang merupakan konsumen yang telah berulang kali mengunjungi Pasar Keramik, namun loyalitas pengunjung menurun untuk kunjungan keempat. Pertimbangan wisatawan untuk mengunjungi Pasar Keramik Belawan adalah jenis barang dagangan yang beragam, sistem tawar menawar secara tradisional, adanya interaksi dengan pedagang langsung, serta penataan ruang belanja yang tidak kaku dengan aksesibilitas sosial berupa penerimaan masyarakat lokal (terutama pedagang) terhadap orang asing. Dari Analisis SWOT yang dilakukan ditemukan bahwa strategi yang dapat dilakukan untuk mengembangkan Pasar Keramik Belawan adalah: membuka toko lebih awal, menambah koleksi barang-barang unik, melakukan ekspansi promosi lewat media sosial, sinergitas pentahelix untuk pengembangan yang lebih efektif, pertimbangan persaingan harga sesuai dengan kualitas barang yang dipasarkan, melengkapi fasilitas (utility) pendukung pariwisata seperti fasilitas penerangan dan peningkatan peran pemerintah dan swadaya komunitas untuk meningkatkan rasa aman bagi pengunjung/wisatawan.
\end{abstract}

\section{Kata Kunci: Pengembangan, wisata belanja, Analisis SWOT}

\section{PENDAHULUAN}

Di era globalisasi ini, persaingan di dalam dunia bisnis semakin pesat. Persaingan bisnis tidak hanya terjadi di Indonesia saja, namun juga terjadi di dunia global yaitu meliputi semua negara-negara yang ada di dunia.Persaingan di dunia bisnis yang diakibatkan adanya globalisasi ini pada akhirnya menuntut setiap negara untuk menonjolkan keunggulan-keunggulan yang dimiliki oleh negaranya masing-masing demi menarik perhatian masyarakat. Agar dapat bertahan di era globalisasi ini, setiap negara tentunya membutuhkan strategistrategi khusus agar negaranya tidak dipengaruhi oleh negara lain. Jika tidak akibatnya akan menjadi fatal.

Untuk mengembangkan pariwisata nasional, sejak dulu pemerintah Republik Indonesia telah gencar mengenalkan program Sapta Pesona. Program ini merupakan cerminan kondisi yang harus diwujudkan dalam rangka menarik wisatawan dalam berkunjung ke suatu daerah atau wilayah Indonesia.

Program yang diluncurkan bersamaan dengan program "Visit Indonesia 1991" ini merupakan konsep yang bertujuan untuk meningkatkan kesadaran tanggung jawab setiap lapisan masyarakat terhadap pembangunan kepariwisataan dan berpartisipasi untuk mewujudkannya. Harapannya adalah untuk meningkatkan kenyamanan wisatawan sehingga berkeinginan untuk tinggal lebih lama lagi di Indonesia. Sesuai namanya, SAPTA PESONA terdiri dari tujuh 
unsur, yaitu keamanan, ketertiban, kebersihan, kesejukan, keindahan, keramah tamahan dan kenangan.

Membuat perjalanan wisata menjadi berkesan sehingga menimbulkan kenangan tersendiri bagi wisatawan merupakan hasil akhir yang dituju dalam program ini. Rasa aman saat berwisata, lalu lintas yang tertib, keadaan yang bersih, objek wisata yang sejuk dan indah, keramah tamahan pelayanan dan masyarakat sekitar akan membuat kenangan berwisata semakin menarik dan manis, sehingga ada ketertarikan untuk datang kembali. Untuk menciptakan sebuah kenangan yang indah, harus ada kesatuan 6 unsur sebelumnya, diantaranya dengan akomodasi yang nyaman, bersih dan pelayanan yang cepat dan ramah serta adanya fasilitas souvenir center yang menyediakan penjualan cenderamata yang khas dan unik.

Bagi banyak wisatawan berbelanja cenderamata merupakan salah satu cara untuk mengenang perjalanan wisata yang dilakukan. Terutama bagi wisatawan domestik yang memiliki profil sebagai wisatawan yang hobi berbelanja. Oleh karena itu, hampir disetiap objek wisata atau destinasi wisata, tidak jarang ditemukan adanya pusat penjualan cenderamata, berupa souvenir center. Sejak dahulu, souvenir center telah menjadi tempat kunjungan "wajib" dalam itenary perjalanan wisata. Inilah yang menjadi cikal bakal tumbuhnya wisata berbelanja.

Wisata berbelanja menjadi salah satu trend wisata saat ini selain wisata kuliner. Wisata belanja memiliki potensi peran untuk menghidupkan perekonomian lokal karena wisatawan mengeluarkan lebih banyak uang di tempat yang dikunjungi. Dengan preferensi dan motivasi wisatawan yang terus berkembang agar kesan yang diperolehnya lebih mendalam. Seiring dengan konsep pariwisata yang berubah, dari konsep mass tourism menjadi konsep ecotourism, dengan 2 sisi pemberdayaan untuk ecology dan economy, maka peran pusat perbelanjaan yang dulunya didominasi pertokoan modern maka sekarang mulai tergeserkan oleh pasar tradisional. Pasar tradisional inilah yang kemudian menjadi nilai tambah bagi peta wisata belanja di Indonesia. Dengan berbelanja di pasar tradisional, tentu saja wisatawan berpeluang untuk mendapatlan harga yang relatif murah. Interaksi dengan penjual dalam transaksi jual beli juga akan menjadi suatu pengalaman sendiri bagi wisatawan.

Hasil data dari NESPARNAS (Neraca Satelit Pariwisata Nasional) tahun 2004, setidaknya ada 4 pasar tradisional yang telah dikembangkan sebagai pusat wisata belanja, yaitu pasar Malioboro Yogyakarta, pasar Kuin/Pasar terapung Bajarmasin, Pasar klewer Solo, dan tentu saja Pasar Gianyar Bali.

Kota Medan juga menjadi salah satu destinasi unggulan yang menarik dan bangunan bersejarah serta ciri khas kuliner menjadi daya tarik tersendiri bagi kota Medan. Jika dikaitkan dengan wisata belanja, maka Medan merupakan salah satu pilihan utama, karena pusat perbelanjaan yang ada sangat beragam, dengan kategori yang tradisional hingga modern.

Salah satu lokasi wisata belanja yang popular di Kota Medan adalah Pasar Keramik Belawan yang terletak di jalan veteran, kelurahan Belawan I. Komoditas yang dijual bukan hanya keramik, namun juga parfum, tas, sepatu, ikat pinggang hingga makanan. Salah satu keunikan Pasar Keramik ini adalah kebanyakan barang yang dijual merupakan komoditas import, kebanyakan dari Malaysia. Tidak heran, karena lokasi Pasar Keramik ini berada dekat Pusat Pelabuhan Belawan. Alur barang yang dipasarkan bukan dari Malaysia langsung, melainkan 
pelabuhan di Batam yang terhubung dengan Malaysia. Sebagai barang import, maka kualitas komoditas dagangan pasar ini dianggap lebih baik dibanding produk lokal.

Keramik sebagai komoditas utama di Pasar Keramik Belawan dianggap jauh lebih baik dibanding keramik lokal, terlebih corak dan ukuran yang bervariasi. Dari komoditas pangan, uniknya produk dengan merek yang sama dengan produk lokal banyak ditemui di pasar ini seperti cincau, nara, grass jelly drink, season, cream crackers, jacob, linux, pop corn, star kist,party, funclub hingga milo. Harga yang ditawarkan bervariasi, ada yang lebih murah, sama bahkan ada yang lebih mahal dibanding produk dengan merek yang sama dijual di pasar biasa. Namun banyak yang meyakini bahwa produk yang dipasarkan di Pasar ini karena diproduksi di Malaysia memiliki citra rasa yang lebih enak.

Dengan uniknya komoditas barang, segmen pasar yang jelas, hingga lokasi yang strategis, sudah selayaknya Pasar Keramik Belawan ini )promosi mengenai keberaaan Pasar Keramik ini. Dalam itenerary resmi paket tour yang dikeluarkan oleh travel agent, juga jarang sekali diadakan kunjungan ke Pasar Keramik Belawan. Bahkan banyak pihak yang menyangsikan aspek legalitas barang yang dijual di Pasar Keramik Belawan ini. Oleh sebab itu, diperlukan kajian mendalam mengenai prospek pengembangan Pasar Keramik sebagai daya tarik wisata belanja di Kota Medan.

\section{METODOLOGI}

\section{Rancangan Penelitian}

Dalam penelitian yang berjudul "Strategi pengembangan Pasar Keramik Belawan sebagai daya tarik wisata belanja di Kota Medan", penulis menggunakan metode deskriptif. Tjahjo (1999) mengungkapkan bahwa metode penelitian deskriptif dimana dengan tujuan dalam gambaran secara sistematis, faktual dan akurat mengenai fakta-fakta dan sifat-sifat dari populasi atau daerah tertentu yang dijadikan objek atau subjek penelitian, sehingga gambaran tersebut merupakan suatu pemikiran tentang pariwisata yang sedang berlangsung pada saat penelitian dilakukan.

Nazir (1998) menjelaskan bahwa metode deskriptif adalah suatu metode yang meneliti suatu set kondisi yang meliputi survey, deskriptif berkesinambungan, studi kasus, analisis pekerjaan dan aktifitas,kaji tindak,penelitian kepustakaan dan dokumenter. Penelitian deskriptif mempelajari tata cara yang berlaku dalam masyarakat, situasi-situasi tertentu, hubungan kegiatan-kegiatan, sika-sikap, pandangan-pandangan dan proses-proses yang sedang berlangsung.

Penelitian deskriptif yaitu penelitian yang berusaha untuk menuturkan pemecahan masalah yang ada sekarang berdasarkan data-data, jadi ia juga menyajikan data, menganalisis dan menginterpretasi. Ia juga bias bersifat komperatif dan korelatif. Penelitian deskriptif banyak membantu terutama dalam penelitian yang bersifat longitudinal, genetik dan klinis. Penelitian survey biasanya termasuk dalam penelitian ini Narbuko dan achmadi (2001).

Dalam metode ini analisis dilakukan pada identifikasi masalah dan penjabaran terhadap data yang dikumpulkan dengan berpedoman pada konsep- 
konsep stufi kepustakaan yang relevan.sehingga dihasilkan deskripsi atau gambaran secara sistematis, faktual, dan akurat mengenai potensi yang dimiliki oleh Pasar Keramik Belawan.

\section{Penelitian Sebelumnya}

Penelitian sebelumnya dengan konsep studi pengembangan objek wisata belanja dengan pendekatan TOWS adalah penelitian yang telah penulis selesaikan pada tahun sebelumnya, yaitu strategi Pengembangan Pasar Tradisional Pajak Ikan sebagai Pusat Wisata Belanja di Kota Medan. Pendekatan TOWS hingga penggunaan matriks QSPM yang digunakan kedua penelitian yang sama. Hanya saja pendekatan konsep teori yang berbeda. Hal ini disebabkan karakteristik tempat penelitian yang berbeda. Pada pajak ikan, pendekatan teori yang digunakan adalah konsep Spillane (2004), yaitu terdiri atas : atraksi, fasilitas, infrastruktur, transportasi dan hospitality. Namun pada penelitian ini pendekatan teori yang digunakan adalah milik Swarbrooke dan Horner (2007) yang terdiri atas: aspek fisik, daya tarik, aksesibilitas, aktivitas, dan fasilitas serta sosial, ekonomi dan budaya. Menurut penulis pendekatan yang digunakan Swarbrooke dan Horner lebih luas dan tidak tumpang tindih, dimana aksesibilitas telah mencakup penjelasan mengenai infrastruktur juga, sehingga tidak perlu sub teori baru untuk itu seperti yang dijumpai pada teori Spillane. Selain itu kajian lain yang mendasari penelitian ini adalah penelitian mengenai wisata sejarah di Kesawan (Liyushiana dan Christina Sianipar, 2017), metode yang digunakan sama dengan Analisis SWOT dan asumsi stratejik namun topik utama penelitian berbeda, karena di Kesawan yang diteliti adalah wisata pusaka, sedangkan untuk penelitian ini menggunakan teori wisata belanja.

\section{Populasi dan Sampel}

Populasi penelitian adalah semua pedagang, konsumen, dan birokrat yang terkait dengan Pasar Keramik Belawan. Namun untuk memudahkan dalam penelitian ini dan agar diperoleh informasi yang lebih mendalam maka akan diambil sejumlah sample saja dari populasi tersebut. Teknik pengambilan sampel dengan teknik random, sehingga setiap populasi memiliki kesempatan yang sama yang sama untuk diteliti. Metode pengambilan sampel untuk responden produsen bersifat simple random sampling sedangkan untuk konsumen sifatnya accidential sampling.

Sedangkan untuk bagian birokrat, maka subjek penelitiannya terbagi manjadi 2, yaitu dinas pariwisata kota Medan dan pihak kepolisian terkait untuk memberikan gambaran untuk aspek legalitas Pasar Keramik Belawan.

\section{Instrumen Penelitian}

Terdapat 2 instrumen penelitian yang akan digunakan pada penelitian ini, yaitu wawancara terbuka dan observasi. Observasi akan dilakukan sejak awal penelitian dengan memantau setiap aspek fisik, daya tarik, aksesibilitas, aktivitas, fasilitas, sosial, ekonomi dan budaya Pasar Keramik Belawan. Setelah mendapat gambaran awal mengenai ancaman, peluang, kelemahan dan kekuatan Pasar Keramik Belawan maka dilakukan wawancara. Wawancara dilakukan kepada pedagang, konsumen dan pihak-pihak yang berkaitan dengan birokrasi serta 
pengembangan daerah. Tujuannya untuk mengidentifikasi ancaman, peluang, kelemahan, dan kekuatan dalam pengembangan Pasar Keramik Belawan.

\section{Pengumpulan Data}

Pengumpulan data dilakukan dengan 4 tahapan, yaitu observasi awal, wawancara pedagang, wawancara konsumen dan wawancara birokrat terkait. Data yang diperoleh berupa data kuantitatif. Beberapa hasil observasi dan wawancara juga dikuantitatifkan sebagai data pendukung penelitian. Pada pengumpulan data ini, penulis dibantu beberapa anggota pembantu penelitian yang rinciannya akan dijelaskan pada bagian personalia.

\section{Metode Analisis Data}

Setelah data terkumpul dari hasil pengumpulan data dan kegiatan penelitian, selanjutnya dilakukan kegiatan menganalisis data. Data kualitatif dan kuantitatif dianalisis dengan tahapan sebagai berikut :

1. Tahap persiapan analisis data

Pada tahap ini dilakukan beberapa kegiatan, antara lain pengecekan isi instrument kelengkapan isi wawancara, isisan data hingga nama dan kelengkapan identitas responden.selanjutnya data dibagi berdasarkan kriteria responden, apakah pedagang,konsumen, birokrat atau hasil observasi.

2. Pencatatan

Setelah tahap persiapan, maka tahap selanjutnya adalah melakukan pencatatan terhadap data yang telah diperoleh melalui proses wawancara dan observasi tersebut.

3. Tahap Pengolahan Data

Analisis data yang digunakan dalam penelitian ini adalah analisa deskriptif.

\section{HASIL DAN PEMBAHASAN}

\section{Gambaran umum Pasar Keramik Belawan}

Medan yang merupakan ibu kota dari Provinsi Sumatera Utara. Kota Medan terletak antara $20.27^{\prime}-20.47^{\prime}$ dan $980.35^{\prime}-980.44^{\prime}$ BT. Kota Medan berada pada ketinggian 2,5 m - 37,5 m diatas permukaan laut. Kota Medan mempunyai iklim tropis dengan berkisar antara 23,3 0C - 33,6 0C.

\section{Tabel 1}

\section{Jumlah Kios di Pasar Keramik Belawan}

\begin{tabular}{|c|c|c|c|c|c|c|}
\hline $\begin{array}{c}\text { Pasar Keramik } \\
\text { Belawan }\end{array}$ & \multicolumn{3}{|c|}{ Jumlah Kios } & \multicolumn{3}{c|}{ Perkembangan (\%) } \\
\hline Tahun & 2016 & 2017 & 2018 & 2016 & 2017 & 2018 \\
\hline Jumlah & 24 & 30 & 36 & 0 & $2 \%$ & $2 \%$ \\
\hline
\end{tabular}

Sumber : Kantor Camat Medan Belawan I

\section{Karakteristik Pengunjung}

Sebagian pengunjung yang datang ke Pasar Keramik Belawan mayoritas dari Sumatera Utara dan Jakarta, Bali dan Bandung. 
Tabel 2

Data pengunjung di Pasar Keramik Belawan berdasarkan usia

\begin{tabular}{|c|c|c|c|c|c|}
\hline \multicolumn{5}{|c|}{ Umur } \\
\hline$<20$ Tahun & $\begin{array}{c}20-30 \\
\text { Tahun }\end{array}$ & $\begin{array}{c}31-40 \\
\text { Tahun }\end{array}$ & $\begin{array}{c}41-50 \\
\text { Tahun }\end{array}$ & $\begin{array}{c}51-60 \\
\text { Tahun }\end{array}$ & $>60$ Tahun \\
\hline $11,3 \%$ & $42,7 \%$ & $24 \%$ & $11,3 \%$ & $4,7 \%$ & $2,7 \%$ \\
\hline
\end{tabular}

Tabel 3.

Data pengunjung di Pasar Keramik Belawan berdasarkan Jenis Kelamin

\begin{tabular}{|c|c|}
\hline \multicolumn{3}{|c|}{ Jenis Kelamin } \\
\hline Laki - laki & Perempuan \\
\hline $54 \%$ & $46 \%$ \\
\hline
\end{tabular}

Tabel 4.

Data pengunjung di Pasar Keramik Belawan berdasarkan tingkat pendidikan

\begin{tabular}{|c|c|c|c|}
\hline SMP & SMA & S1 & S2 \\
\hline $2 \%$ & $3,3 \%$ & $51,3 \%$ & $43,3 \%$ \\
\hline
\end{tabular}

Tabel 5

Data pengunjung di Pasar Keramik Belawan berdasarkan frekuensi berkunjung

\begin{tabular}{|c|c|c|}
\hline No. & Jumlah Frekuensi Berkunjung & Persentase \\
\hline 1 & Kunjungan pertama & $25,3 \%$ \\
\hline 2 & Kunjungan kedua & $34 \%$ \\
\hline 3 & Kunjungan ketiga & $21,3 \%$ \\
\hline 4 & Kunjungan keempat & $5,3 \%$ \\
\hline 5 & Kunjungan lebih dari empat kali & $14 \%$ \\
\hline
\end{tabular}

Dari tabel diatas bisa diambil kesimpulan bahwa wisatawan sebagaian besar yang berkunjung ke Pasar Keramik Belawan yaitu wisatawan yang bersifat yang datang dengan berulang kali kunjungan. Hal inilah yang membuat bahwa Pasar Keramik Belawan memiliki potensi sebagai wisata yang bisa diperhitungkan.

Tabel 6.

Data pengunjung di Pasar Keramik Belawan berdasarkan jenis pekerjaan

\begin{tabular}{|c|l|c|}
\hline No & \multicolumn{1}{|c|}{ Jenis Pekerjaan } & Persentase \\
\hline 1 & Wiraswasta & $23 \%$ \\
\hline 2 & Pegawai swasta & $20 \%$ \\
\hline 3 & PNS & $20,7 \%$ \\
\hline 4 & Pelajar/Mahasiswa & $19,3 \%$ \\
\hline
\end{tabular}


Tabel 7

Data pengunjung di Pasar Keramik Belawan berdasarkan penghasilan

\begin{tabular}{|c|c|c|}
\hline No. & Jumlah Penghasilan & Persentase \\
\hline 1 & Rp. $1.000 .000-3.000 .000$ & $42,7 \%$ \\
\hline 2 & Rp.3.000.100-5.000.000 & $20 \%$ \\
\hline 3 & Rp.5.000.100-7.000.000 & $5,3 \%$ \\
\hline 4 & Rp.7.000.100-9.000.000 & $0,7 \%$ \\
\hline 5 & $>$ Rp.9.000.000 & $24,7 \%$ \\
\hline
\end{tabular}

Keberadaan Pasar Keramik Belawan terhadap Pariwisata dan Masyarakat

Pariwisata di Indonesia saat ini menjadi salah satu sektor perekonomian yang menjadi prioritas dalam pembangunan di Indonesia sesuai amanat Presiden Indonesia, Bapak Joko Widodo. Bebragai prestasi perkembangan pariwisata telah ditunjukkan dengan naiknya peringkat daya saing pariwisata Indonesia pada peringkat ke-40 dari 140 negara versi World Economic Forum (WEF). Namun demikian perkembangan wisata minat khusus dengan tujuan belanja menunjukkan loyalitas cukup rendah, yaitu sekitar 28\% (Bunga Astari, 2015).

Pada atraksi wisata Pasar Keramik Belawan, hal ini terlihat dari tabel data pengunjung di Pasar Keramik Belawan berdasarkan frekuensi berkunjung yang emnunjukkan jumlah yang merosot tajam pada kunjungan keempat, yaitu pada angka 5\%. Hal ini cukup disayangkan mengingat beragam pihak sudah turut andil dalam upaya peningkatan loyalitas belanja agar frekuensi belanja berulang dapat terjadi secara simultan di Pasar Keramik Belawan.

Faktor utama yang menjadi pertimbangan para wisatawan untuk berkunjung di Pasar Keramik Belawan adalah : jenis barang dagangan yang menjadi kekhasan lokal yang meliputi komoditas keramik baik alat rumah tangga maupun keramik sebagai hiasan dan cindera mata berupa barang antik, model perbelanjaan yang masih tradisional dengan pola tawar menawar dan kontak langsung dengan penjual akan menambah kepuasan para wisatawan dalam berbelanja. Model penataan ruang atau setting ruang yang tidak formal atau kaku, sehingga para wisatawan dapat berlama-lama tanpa merasa sungkan dengan pelayanan yang ramah dan sabar dari penjual, fasilitas pendukung dan fasilitas umum yang memadai sehingga para wisatawan nyaman berbelanja serta pusat onformasi yang lengkap dan jelas bagi produk-produk khas lokal dan cinderamata.

Keberadaan pasar tradisional Keramik Belawan dapat meningkatkan kegiatan pariwisata dan ekonomi kreatif yang memiliki kaitan yang sangat erat. Hal ini dapat dilihat misalnya untuk wisatawan yang datang kePasar Keramik Belawan, wisatawan dari dalam atau luar negeri. Setiap wisatawan beli satu saja oleh-oleh, maka dapat diperkirakan berapa oleh-oleh yang tercipta.

Dengan demikian semakin banyak wisatawan yang berkunjung ke Pasar Keramik Belawan ini maka semakin besar pula peningkatan pendapatan para penjual disini. Sehingga perlu juga di pertimbangkan kenyamanan bagi wisatawan yang berkunjung ke Pasar Keramik Belawan ini, agar semakin menjadi dapat menguntungkan bagi pihak penjual dan wisatawan. 


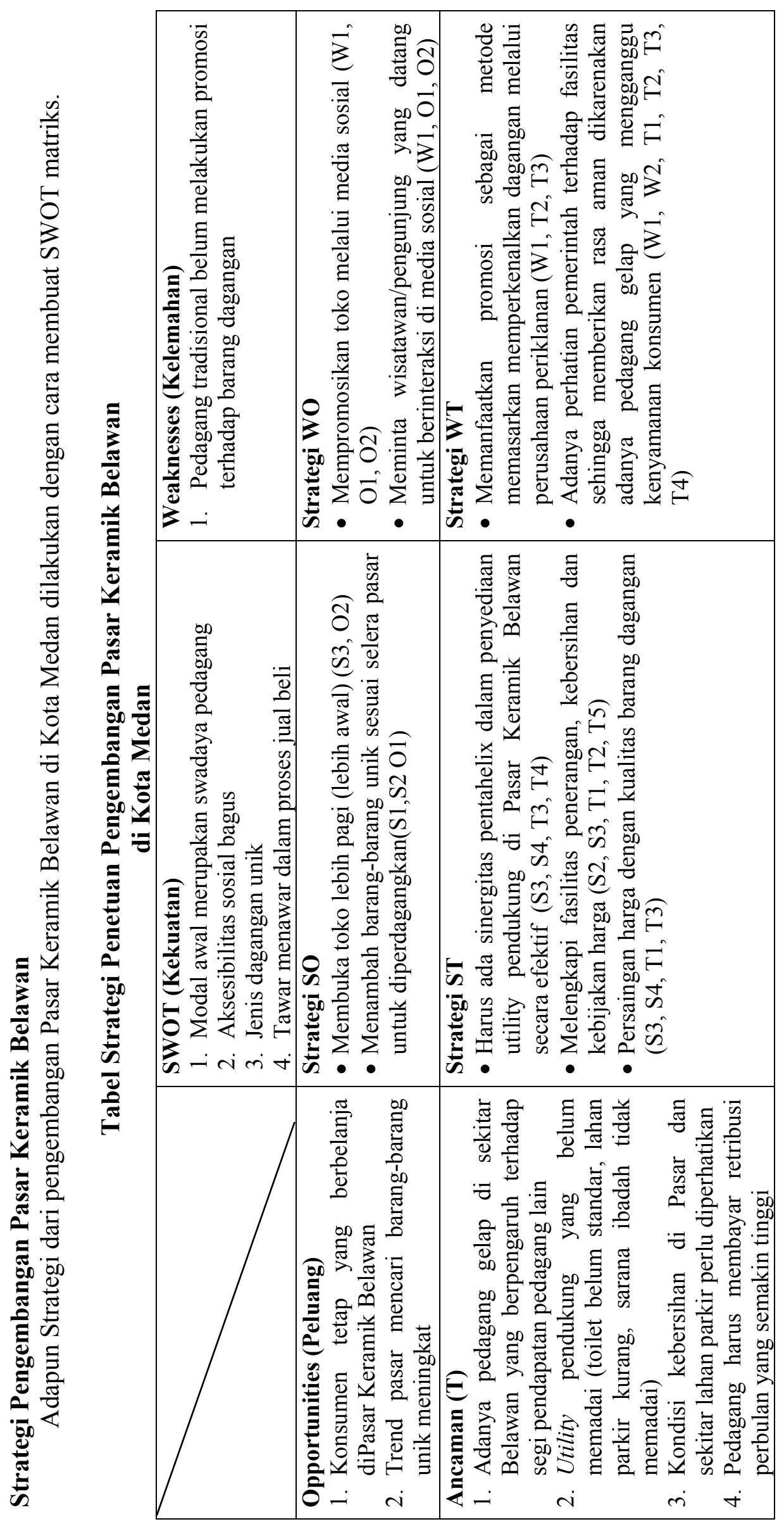




\section{SIMPULAN}

Dalam merumuskan strategi pengembangan Pasar Keramik Belawan, hal yang harus diperhatikan adalah jenis barang dagangan yang menjadi kekhasan yang meliputi komoditas keramik, dan cindera mata berupa barang antik, model perbelanjaan yang masih tradisional dengan pola tawar menawar dan kontak langsung dengan penjual, akan menambah kepuasan para wisatawan dalam berbelanja, kodel penataan ruang atau ruang yang tidak formal atau kaku, sehingga para wisatawan dapat berlama-lam tanpa merasa sungkan dengan pelayanan yang ramah dan sabar dari penjual. Fasilitas pendukung dan fasilitas umum yang kurang memadai sehingga para wisatawan tidak dapat nyaman berbelanja serta adanya pusat informasi yang lengkap dan jelas bagi produkproduk khas lokal dan cinderamata.

Adanya pedagang gelap yang berada di sekitar pelabuhan Belawan adalah salah satu ancaman bagi keberadaan Pasar Keramik Belawan ini. Sehingga dihimbau untuk dapat segera ditertibkan oleh pihak terkait.

Untuk keberhasilan pengembangan Pasar Keramik Belawan maka saran yang diajukan adalah : semua pihak yang terkait harus dilibatkan, baik komunitas pedagang, pengunjung, maupun masyarakat Kota Medan pada umumnya. Dewasa ini dikembangkan konsep sinergitas pentahelix yang dapat diterapkan dalam pengembangan Pasar Keramik Belawan dengan mengikutsertakan pemerintah, komunitas, industri, akademisi dan media. Fasilitas dasar sebuah daya tarik wisata seperti fasilitas penerangan dan kebersihan perlu menjadi prioritas. Dan salah satu langkan agar Pasar Keramik Belawan tetap kompetitif adalah dengan menetapkan kebijakan harga, misalnya dengan menetapkan harga eceran tertinggi untuk semua produk sehingga pengunjung merasa dilindungi dan mengurangi upaya penipuan yang akan berujung pada rusaknya reputasi Pasar Keramik Belawan di kemudian hari. Selain itu, penerapan sapta pesona dengan menitik beratkan pada aspek keindahan suasana, kenyamanan, kebersihan dan ketertiban serta keramahtamahan menjadi prioritas dalam menyambut wisatawan. Koordinasi antar obyek wisata yang ada di Belawan Medan dan fasilitas penunjang lainnya. Dampak positif harus dapat dimanfaatkan sebaikmungkin. Serta dukungan pemerintah kota yang tiada hentinya untuk tetap memperhatikan sarana dan prasarana jalan menuju ke lokasi perbelanjaan. Sehingga apa yang terjadi menjadi harapan para pengunjung/pembeli minimal dapat terpenuhi.

\section{DAFTAR PUSTAKA}

Astari, B. (2015). Pengaruh Store Attribute terhadap Loyalitas Wisatawan dikontrol oleh Motivasi Belanja. Universitas Pendidikan Indonesia.

Bovy, M. B., \& Lawson, F. R. (1998). Tourism and Recreation Handbook of Planning and Design. Elseveiver.

Bukart, A. J., \& Medlik, S. (1974). Tourism: Past, Present and Future.

Dalimunthe, F. I. (2009). ANalisis Pengaruh Promosi dan Komunikasi terhadap Pengambilan Keputusan Tamu (Occupant) untuk Memilih Menginap di Hotel Tiara Medan. MS Thesis. 
Dalimunthe, F. I. (2011). Studi Pengembangan Pasar Tradisional Pajak Ikan sebagai Pusat Wisata Belanja di Kota Medan. Jurnal Akademi Pariwisata Medan.

Danurdara, A. B., Nurdin, H., \& Masatip, A. (2017). How Does Strong Experiental Marketing Affect the Customer Value? International Journal of Marketing Studies, 9(4), 89-96.

Foster, D. L. (2000). An Introduction to Travel and Tourism. Raja Grafindo Persada.

Kementerian Kebudayaan dan Pariwisata. (2004). Neraca Satelit Pariwisata Nasional.

Kementerian Pariwisata. (2009). Undang-undang tentang Kepariwisataan (No. 10 Tahun 2009).

Koontz, H., \& Weirich, H. (2007). Essential of Management. Tata Mc. Graw Hill. Liyushiana, L. (2019). Kajian Pola Perjalanan Wisata Di Kabupaten Nias Barat, Sumatera Utara. Khasanah Ilmu - Jurnal Pariwisata Dan Budaya, 10(2). https://doi.org/10.31294/khi.v10i2.6374

Liyushiana, L., Rizkiyah, P., \& Herman, H. (2019). Daya Tarik Wisata Pascabencana Erupsi Gunungapi Sinabung Di Kabupaten Karo, Sumatera Utara. Jurnal Destinasi Pariwisata, 7(2), 421. https://doi.org/10.24843/jdepar.2019.v07.i02.p29

Narbuko, C. (2004). Metodologi Penelitian (6th ed.). Bumi Aksara, Jakarta.

Rizkiyah, P., Liyushiana, L., \& Herman, H. (2019). Sinergitas pentahelix dalam pemulihan pariwisata pasca bencana erupsi gunung api sinabung Di kabupaten karo, sumatera utara. Jurnal IPTA, 7(2), 247. https://doi.org/10.24843/ipta.2019.v07.i02.p15

Sebastiana Sitompul, S., Indriani Dalimunthe, F., \& Muhammad, H. I. (2019). The importance of the soft skill influence for the tourism community for the satisfaction of tourists at Parbaba beach in Samosir island. Proceedings of the 1st International Conference One Belt, One Road, One Tourism (ICOBOROT 2018). https://doi.org/10.2991/icoborot-18.2019.25

Soegiri, H. (2010). Konsep Pikir TOWS, bukan SWOT. Kencana Perca.

Spillane, J. J. (1994). Pariwisata Indonesia: Siasat Ekonomi Dan Rekayasa Kebudayaan. Kanisius. 